\title{
A Filosofia no Ensino Médio: Por que, o que e como ensiná-la?
}

Thiago Cruz da Silva

\section{Resumo:}

Com a promulgação da Lei II.684, a Filosofia volta a ser uma disciplina obrigatória nas escolas brasileiras. Frente a esse cenário, profissionais envolvidos com o ensino, especialmente professores de Filosofia, são novamente convocados a pensar questões fundamentais sobre a disciplina: é preciso saber por que, afinal de contas, deve-se ensiná-la para os jovens do ensino médio, e quais conteúdos e metodologias devem ser empregados para atingir esses objetivos. Não há dúvida de que diante de uma infinidade de possibilidades, tanto em relação à escolha de métodos como à de conteúdos e fins, esses professores deparam-se com os problemas centrais que há pouco enunciamos. É precisamente nesse registro que se insere a presente investigação: trata-se de uma série de reflexões acerca do espaço da Filosofia nas escolas.

Palavras-chave: Ensino - Filosofia - Ensino Médio. 
Com a promulgação da Lei II.684, de 2 de junho de 2008, a Filosofia ${ }^{\mathrm{I}}$ volta a ser uma disciplina obrigatória nas escolas brasileiras, função que ela não desempenhava desde I96I (Lei ${ }^{0}$ 4.020/6I). Segundo a nova lei, o ensino de Filosofia (assim como o de Sociologia) assume um caráter de obrigatoriedade em todas as séries do ensino médio, a última etapa da educação básica no país. Diante desse cenário, profissionais envolvidos com o ensino, principalmente com o ensino de Filosofia - sejam eles professores universitários, de ensino médio ou mesmo estudantes - são novamente convocados a pensar questões fundamentais sobre a disciplina: é preciso saber por que, afinal de contas, deve-se ensinar Filosofia para os jovens do ensino médio, e quais conteúdos e metodologias devem ser empregados para atingir esses objetivos.

Se essas são perguntas ainda em aberto, isso se deve ao fato de a Filosofia não ter se desenvolvido plenamente como disciplina, para o que lhe teria sido necessária uma base institucional estável que a reconhecesse como integrante do currículo escolar brasileiro em caráter de obrigatoriedade. A Filosofia, portanto, é uma disciplina cuja situação difere essencialmente de outras áreas mais tradicionais, como o Português, a Matemática, a Biologia, que tiveram sua identidade construída ao longo dos anos. É bem verdade que alguns esforços têm sido feitos no sentido de oferecer respostas àquelas questões. Um exemplo disso são as publicações oficiais, como os Parâmetros Curriculares Nacionais (PGN de I999, PGN+ de 2002). O novo quadro institucional em que nos encontramos sugere, porém, que é preciso mais do que indicações acerca dos fins que se pode/ deve atingir com a Filosofia como componente curricular do ensino médio.

Nesse sentido, as Orientações Curriculares para o Ensino Médio, de 2008, constituem-se como um importante material para quem pensa sobre o assunto, especialmente para aqueles que estão ou estarão em breve nas escolas na condição de professores da área. Esse é o caso dos estudantes brasileiros matriculados nos cursos de Licenciatura em Filosofia. Diante de uma infinidade de possibilidades tanto em relação à escolha de métodos como à de conteúdos e fins - o que se deve à ausência de bons materiais didáticos sobre o tema - e na iminência da realização de seus estágios, esses futuros professores deparam-se com os problemas centrais que há pouco enunciamos: por que, o que e como ensinar Filosofia? É precisamente nesse registro que se insere a presente investigação: trata-se de uma série de reflexões acerca do espaço da Filosofia nas escolas, uma tentativa bastante incipiente de responder às questões centrais sobre a importância da Filosofia para o ensino médio.

\footnotetext{
I Filosofia de que tomamos partido neste trabalho diz respeito tanto aos problemas tratados nos textos clássicos, como ao tipo de análise que os filósofos da tradição empreenderam. Isso, porém, não nos compromete com um ou outro sistema filosófico, nem mesmo com a adoção deste ou daquele livro.
} 
Uma resposta propriamente filosófica por certo requer argumentação. Desse modo, este trabalho poderá ser visto, sem equívoco de interpretação, como uma defesa acerca do espaço da Filosofia nas escolas brasileiras, dos conteúdos e da metodologia a serem empregados por essa disciplina. Os materiais que serviram de base para a sua realização foram, especialmente, o texto da Lei de Diretrizes e Bases da Educação Nacional (Lei n. ${ }^{\circ}$ 9.394/96) e o texto das Orientações Curriculares para o Ensino Médio, ${ }^{2}$ publicado pelo Ministério da Educação em 2008.

O texto divide-se em dois capítulos. No primeiro capítulo, "Por que a filosofia deve ter espaço no ensino médio?", ofereço uma resposta positiva a essa questão seguindo uma linha um pouco diferente daquela adotada por Matthew Lipman em Filosofia vai à escola ${ }^{3}$ segundo a qual a Filosofia teria um papel central no projeto educacional como um todo. Defendo que, além de sua contribuição para a formação de cidadãos - o que, aliás, está entre os objetivos gerais da educação básica, não sendo, portanto, uma exclusividade sua - a Filosofia é uma disciplina que realiza plenamente a finalidade expressa no Inciso III do artigo 35 da LDB (artigo em que são expostas as finalidades do ensino médio), ou seja, "o aprimoramento do educando como pessoa humana, incluindo a formação ética e o desenvolvimento da autonomia intelectual e do pensamento crítico”. Não se trata, portanto, de ver a Filosofia como uma disciplina cujo objetivo central é formar pessoas para que elas adquiram uma disposição para agir conforme a cidadania ou conforme o interesse público. Seu papel é muito mais abrangente: ela é capaz de promover a formação geral dos indivíduos por meio do desenvolvimento do pensamento crítico.

No segundo capítulo, defendo a importância da História da Filosofia como ponto de apoio para a escolha dos conteúdos a serem trabalhados nas escolas (e, tanto quanto possível, do acesso aos textos clássicos), e teço algumas considerações acerca da metodologia a ser utilizada para abordar essas temáticas. De maneira geral, sugiro que, independentemente da estratégia pedagógica adotada pelo professor, deve-se sempre impedir que o contato inicial do estudante com um problema filosófico se dê mediante a leitura do texto clássico, algo que seria desastroso. É preciso que os jovens primeiramente tomem para si os problemas, o que pode ser estimulado de diversas maneiras, para só então apresentar-lhes as soluções propostas pelos filósofos da tradição, as quais devem ser objeto de sua interpretação e também de seu julgamento.

2 Por economia, na continuação do texto mencionaremos essa obra simplesmente como "Orientações Curriculares".

3 LIPMAN, Matthew. A Filosofia vai à Escola; tradução de Maria Elice de Brzezinski Prestes e Lucia Maria Silva Kremer - São Paulo: Summus Editorial, I990. 


\section{Por que a Filosofia Deve Ter Espaço no Ensino Médio?}

Costuma-se dizer que, em razão da ausência ou escassez de profissionais qualificados, fazer da Filosofia um componente curricular das escolas brasileiras, quanto mais em caráter de obrigatoriedade, seria adotar uma medida, se não improfícua, ao menos perigosa: sua má condução serviria para doutrinar em vez de promover o desenvolvimento de pessoas intelectualmente autônomas. Ora, a falácia desse raciocínio consiste em que é perfeitamente possível concordarse acerca da necessidade de profissionais qualificados na área para que bons resultados sejam atingidos por essa disciplina; que, além disso, há escassez desses profissionais (o que não parece ser o caso) sem, contudo, aceitar sua conclusão, segundo a qual a Filosofia não deveria ser introduzida no currículo escolar, dizendo simplesmente: "Se é qualificação que está faltando, e se é esta uma disciplina que contribui efetivamente para o desenvolvimento do educando, aos estudos, pois!". Acrescente-se a isso a expansão dos cursos de graduação que atualmente vem ocorrendo nas Universidades brasileiras e teremos menos razões para levar a sério tal objeção.

De fato, não é preciso muito tempo para se perceber a fraqueza de alguns dos argumentos relacionados a essa discussão. O do parágrafo anterior é um exemplo disso: não se pode recusar a condição de disciplina escolar à Filosofia alegando unicamente que existem poucas pessoas capazes de ensiná-la adequadamente, mesmo que este seja o caso. Oferecer maus argumentos, porém, não é exclusividade daqueles que se opõem à Filosofia no ensino médio. Assim, poder-se-ia dizer que a Filosofia deve ter lugar nas escolas apelando simplesmente para o - recentemente estabelecido - caráter legal desse procedimento, ou seja, dizendo que porque a lei determina (o que em parte é uma boa razão), a Filosofia deve ser ensinada para os jovens nas escolas do país. Ora, como nos mostra a experiência, ninguém ficaria satisfeito ao ouvir de seu interlocutor algo semelhante. Isso porque uma resposta nesses termos legitima a introdução da seguinte questão, a qual, de certo modo, repõe o problema: Por que, afinal de contas, existe e deve existir uma lei que determine a presença da Filosofia no currículo escolar oficial para o ensino médio? Responder a essa questão, assim reformulada, é nosso objetivo neste capítulo. E aqueles que se contentarem com quaisquer das respostas enunciadas há pouco deverão ter em mente seu caráter falacioso.

\section{I}

Em A Filosofia vai à Escola, Matthew Lipman realiza uma série de reflexões acerca da situação educacional dos EUA da década de 80. Como alternativa àquele quadro, ele apresenta uma proposta segundo a qual a escola - o 
sistema educacional como um todo - deveria ser reorganizada com vistas a desenvolver uma "educação para o pensar", ou seja, uma educação que visasse não ao acúmulo de informações, mas ao desenvolvimento de habilidades de pensamento $^{4}$. Segundo esse projeto, a Filosofia teria um papel central nas escolas, sendo encarada como disciplina obrigatória já no ensino fundamental. Ademais, todas as disciplinas deveriam adotar uma postura filosófica em relação ao conjunto de conhecimentos de que se ocupam, investigando seus próprios fundamentos, métodos e, por que não, as soluções para os problemas que ordinariamente se lhes apresentam. Apesar da enorme relevância e da boa justificação apresentada por Lipman, um projeto como o seu, que diz respeito à escola como um todo, não é o que temos em mente neste trabalho. Aqui, interessa-nos apenas defender a importância da Filosofia como disciplina do currículo escolar para a formação dos indivíduos, e não como uma disciplina cujo modo de proceder deva ser adotado por toda a escola, o que, dado o caráter de nossa pesquisa, seria muita pretensão.

No entanto, há um ponto em especial (entre tantos outros) que chama a atenção naquele livro: a importância que Lipman concede à Filosofia no processo de formação de cidadãos, e de bons cidadãos. Com efeito, há um capítulo cujo título é "Educação para os valores cívicos", no qual o autor defende não um conjunto determinado de valores, mas o desenvolvimento de habilidades de pensamento requeridas para quem quer que se pretenda um bom cidadão, como a capacidade de conversação em grupos, de autocorreção contínua em relação a debates sobre ética, bem como a disposição para agir conforme a racionalidade expressa nas instituições públicas democráticas, habilidades que somente são alcançadas, segundo ele, mediante a exposição sistemática das pessoas ao exercício comum do raciocínio. Assim, muito porque a Filosofia contribuiria para a formação de bons indivíduos enquanto cidadãos, ela deveria ser adotada pelas escolas.

Nessa mesma linha, a Lei de Diretrizes e Bases da Educação Nacional (Art. 22) afirma que uma das finalidades da educação básica é "desenvolver o educando" e "assegurar-lhe a formação comum indispensável para o "exercício da cidadania". Com uma ênfase um pouco diferente dessas duas abordagens, nosso argumento em favor do ensino de Filosofia não consiste tanto na indicação de sua contribuição para a prática da cidadania por parte dos indivíduos (embora esta seja uma das finalidades da educação básica e apesar de a Filosofia colaborar com sua realização), como no fato de que, mais do que qualquer outra disciplina, a Filosofia promove "o aprimoramento do educando

4 LIPMAN, Matthew. A Filosofia vai à Escola; tradução de Maria Elice de Brzezinski Prestes e Lúcia Maria Silva Kremer - São Paulo: Summus Editorial, I990, p. 47. 
como pessoa humana, incluindo a formação ética e o desenvolvimento da autonomia intelectual e do pensamento crítico", um dos objetivos do ensino médio segundo a LDB, com o qual estamos plenamente de acordo. Como se disse, isso não significa que a Filosofia não contribua ou não seja importante para a formação de bons cidadãos, mas apenas que seu papel não se restringe a isso. Resumidamente, portanto, a Filosofia deve ter espaço no ensino médio porque, se comparada a outras disciplinas, ela é quem melhor realiza o disposto no Inciso III do Art. 35 da LDB.

Por certo, a essa primeira formulação da resposta não faltariam objeções. Muitos fatalmente se sentiriam tentados a questionar: "Será que a Filosofia contribui realmente para a realização daqueles fins?". "Supondo que esse seja o caso, por que ela deveria ser ensinada nas escolas, simplesmente porque contribui para uma das finalidades do ensino médio segundo uma lei?"; e ainda: "Se esta resposta for afirmativa, não se estará incorrendo no erro que há pouco acusamos, ou seja, não se estará recorrendo a um expediente sofístico para justificar seu lugar nas escolas brasileiras?” Tais questões, longe de nos serem indesejáveis, servirão como fio condutor para o nosso raciocínio em favor da Filosofia no ensino médio. Assim, mostraremos, em primeiro lugar, que a Filosofia realiza aqueles fins e, em seguida, que é porque aquelas são habilidades que estimamos por si mesmas que a lei as prescreve, de modo a mandar para longe qualquer acusação de que nossa resposta é em alguma medida inadequada.

\section{II}

Segundo o Inciso III do Art. 35 da LDB, um dos objetivos do ensino médio é "o aprimoramento do educando como pessoa humana", ou seja, como sujeito ético, intelectualmente autônomo, cujo pensamento é crítico, como mostra a continuação daquele texto. Ora, quem quer que se tenha familiarizado com o empreendimento filosófico - seja por meio da leitura dos clássicos, seja por uma tendência natural a pensar detidamente sobre questões intrigantes - não terá nenhuma dificuldade em reconhecer que a Filosofia estimula e desenvolve nas pessoas o senso crítico, algo que é essencial para que elas atinjam sua autonomia intelectual. Com efeito, pensar por si não significa ter ideias diferentes das de todos os seres humanos, mas apenas que, diante dos pensamentos alheios (de filósofos ou não-filósofos), o indivíduo intelectualmente autônomo adota não adota uma postura passiva: ele exige que tais pensamentos sejam acompanhados de razões; que, além disso, sejam boas essas razões, para, somente então, darlhes assentimento. Desse modo, ele é primeiro crítico, e então autônomo.

Segundo uma tradição inteira de pensamento, o exercício propriamente filosófico consiste no engajamento em questões para as quais a mente humana 
naturalmente desperta, diante do que somos tentados a buscar respostas que convençam não apenas aos outros, como a nós mesmos. É característico da Filosofia problematizar lugares-comuns valendo-se do uso sistemático da pergunta "Por quê?" Ela nos ensina a ter aversão pelas meras opiniões, pela ausência de fundamento, pelo dogmatismo cego. Por essa mesma razão, seu exercício contribui para a formação de indivíduos éticos, que quando envolvidos em questões morais sentem a necessidade da justificação, de uma base racional para escolher qual alternativa terá lugar em suas ações Ademais, a Filosofia nos ensina a sermos críticos e isso não significa tudo criticar, no sentido em que estamos habituados a utilizar esse termo. Caso contrário, os jovens, especialmente os adolescentes, não teriam a necessidade de realizar quaisquer esforços para se tornarem intelectualmente críticos e autônomos. A Filosofia, diferentemente do que se costuma pensar, estimula um senso crítico que difere essencialmente de posturas céticas e preconceituosas: procedendo filosoficamente, não se pode recusar uma teoria ou argumento sem antes compreendê-los. Seu exercício nos ensina como regra de método primeiro entender os textos para, somente então, avaliá-los.

Se, portanto, a compreensão é requerida para que os indivíduos possam se desenvolver como sujeitos críticos e autônomos, intelectualmente falando, sendo a Filosofia especialmente eficaz nesse processo, não se lhe pode recusar um espaço na escola, sobretudo em nosso país, onde a maioria dos jovens sai da escola sem sequer ter desenvolvido a capacidade de compreender o que lê. Logo, a Filosofia deve ter espaço no ensino médio (e, se possível, não apenas nesse nível de ensino) porque ela é capaz de formar indivíduos intelectualmente autônomos, que pensem por si mesmos, para o que é necessário o estímulo à postura crítica, algo que, por sua vez, só é possível quando se tem desenvolvida a habilidade de ler e interpretar textos, o que mais propriamente constitui o objeto e método filosóficos. A introdução dessa disciplina nas escolas auxiliará os jovens na identificação e avaliação de argumentos e opiniões sobre quaisquer assuntos, bem como os estimulará a criarem por si mesmos seus próprios argumentos, tornando-os assim pessoas intelectualmente autônomas. Compreender, questionar, avaliar e criar argumentos sistematicamente, habilidades que são desenvolvidas mediante o estudo da Filosofia e que estão entre os objetivos do ensino médio segundo o Inciso III do Art. 35 da LDB, ainda que expressas por outros termos.

Com efeito, que a Filosofia auxilie no desenvolvimento daquelas habilidades, uma rápida análise do modo como procedem aqueles que se dedicam a seu estudo prova suficientemente. No entanto, pode-se legitimamente perguntar por que tais habilidades devem ser visadas pela educação. Em outras palavras: Por que "o aprimoramento do educando como pessoa humana, incluindo a formação ética e o desenvolvimento da autonomia intelectual e do pensamento 
crítico" é algo em vista do que se deve organizar a escola, especificamente o ensino médio? Por certo, depois de ter acusado o golpe por mais de uma vez, não poderíamos nos contentar em responder a essas questões apelando unicamente para o aspecto jurídico em que se assenta a educação nacional, do mesmo modo que não pudemos nos valer unicamente do caráter legal do ensino de Filosofia para justificar sua presença no ensino médio.

Quanto a esse ponto, porém, pouca coisa precisará ser dita. A Filosofia deve ter lugar no currículo escolar oficial em caráter de obrigatoriedade porque ela é uma disciplina que contribui para o desenvolvimento dos indivíduos como sujeitos éticos (não no sentido de que tais indivíduos sempre agirão corretamente, mas no sentido de que agirão conforme o pensamento, segundo razões) e como pessoas intelectualmente autônomas (capazes de formular os próprios argumentos e de defenderem racionalmente suas posições), que estão acostumadas ao empreendimento crítico (que têm repulsa pela mera opinião e pela conduta injustificada), qualidades que nós estimamos por si mesmas, não porque a lei determina, e isso em virtude do modo como somos constituídos, ou seja, humanamente falando. Pois haverá qualidade mais desprezível em uma pessoa do que sua disposição para concordar passivamente com quaisquer pensamentos alheios, sem pedir maiores esclarecimentos sobre nada do que se diz? Ou será que, por causa de um relativismo contemporaneamente em voga, deixaremos de apreciar e elogiar indivíduos que pensam por si mesmos? Assim, é porque nós naturalmente as apreciamos que aquelas qualidades devem ser finalidades a serem atingidas pela escola e, particularmente, pelo ensino de Filosofia.

Ora, do mesmo modo que o senso comum e a posição dogmática são para nós atitudes desprezíveis, algo de que temos aversão, assim também o indivíduo intelectualmente autônomo se nos apresenta como objeto de admiração, e isso é uma questão de fato. Ademais, além desse agrado imediatamente produzido em nós pela contemplação de tal indivíduo, tais qualidades são favoráveis à manutenção do Estado democrático em que vivemos, na medida em que se opõem à adesão irrefletida dos indivíduos a movimentos de massa, às ditaduras e totalitarismos dos quais a História nos dá muitos exemplos. De fato, muito do apreço que temos por pessoas que atingiram a maioridade (para adotar uma linguagem kantiana) deriva de sua disposição favorável à manutenção de um tipo de sociedade que julgamos ser o mais justo para os seres humanos.

Portanto, é porque as estimamos por si mesmas, seja por utilidade ou por um agrado imediato, que qualidades como o pensamento crítico e a autonomia intelectual devem ser visadas pela educação. Dada a contribuição da Filosofia para a realização e o desenvolvimento dessas habilidades, estabelecemos a conclusão segundo a qual a Filosofia deve ter espaço não apenas no ensino médio, mas também nos outros níveis da educação básica, se houver recursos 
para isso. Sua presença nas escolas sem dúvida será mais justificada do que a de outras disciplinas mais tradicionais, cujos objetivos se perderam ao longo dos anos.

\section{Conteúdos e Métodos para o Ensino de Filosofia}

Uma vez estabelecida a conclusão segundo a qual a Filosofia tem lugar nas escolas brasileiras, surge imediatamente a seguinte questão: de que modo a disciplina deve ser organizada para atingir aqueles fins que esperamos que ela realize? Em outras palavras: o que e como se deve ensinar Filosofia para que os estudantes se tornem pessoas intelectualmente críticas e autônomas? No presente capítulo, proponho algumas reflexões acerca dos conteúdos e métodos a serem empregados por esta disciplina no ensino médio.

No que diz respeito aos conteúdos a serem utilizados nas aulas de Filosofia, segui a sugestão das Orientações Curriculares, segundo a qual "Cabe insistir na centralidade da História da Filosofia para o tratamento adequado de questões filosóficas", 5 bem como o acesso aos textos clássicos, pois desse modo mantém-se a especificidade da disciplina e do exercício de análise propriamente filosófico, sem o que a Filosofia não contribuiria para o desenvolvimento daquelas habilidades em razão das quais defendemos seu espaço nas escolas, dando margem à postura dogmática por parte dos professores. Essa posição reafirma, consequentemente, a necessidade de formação específica para o professor de Filosofia, algo que é requerido para se ter um bom acesso ao texto filosófico clássico: diferentemente do que se poderia pensar, o empreendimento filosófico não é algo a que estejamos todos desde sempre habilitados a fazer corretamente, quanto mais a condução de uma aula sobre tais assuntos. Temos, portanto, uma continuação do raciocínio precedente: a Filosofia defendida há pouco como de grande valor para a formação dos indivíduos não era senão a Filosofia tal como tradicionalmente a conhecemos, ou seja, a Filosofia dos (e como a dos) grandes tratados filosóficos.

Em relação à metodologia, minha sugestão é de caráter bem geral: sustento que, apesar da centralidade dos textos clássicos e da História da Filosofia, a disciplina deverá ser conduzida de modo a impedir que o primeiro contato dos estudantes com os mais variados problemas filosóficos se dê mediante a leitura prematura daqueles textos, o que seria no mínimo desestimulante, dada a aridez de que eles são dotados. O objetivo aqui passa ao largo de defender esta ou aquela estratégia pedagógica (se aulas expositivas, seminários, atividades em grupo etc.) como intrinsecamente superior às demais, o que deve ficar a critério de cada professor. Em vez disso, defendo que, seja qual for esse recurso, é indispensável

5 Orientações Curriculares, p. I7. 
que os alunos primeiro adquiram alguma familiaridade com os conteúdos e problemas filosóficos de maneira mais informal para, somente então, entrarem em contato com o texto clássico, situação em que eles deverão ser instruídos de modo a não apenas compreenderem, como também avaliarem o raciocínio dos grandes filósofos. Mesmo então, deve-se ter o cuidado de não se exigir dos alunos do ensino médio nem o mesmo grau de aprofundamento, nem a mesma carga de leitura exigida nos cursos de graduação em Filosofia, o que pode ser uma tentação para qualquer professor. $O$ ensino de Filosofia nas escolas não pode ser uma simples reprodução do que se faz nos cursos universitários, nem é desejável que o seja: além do público ser diferente, o ensino médio (e a educação básica como um todo) tem seus objetivos próprios.

\section{I}

Segundo as Orientações Curriculares, "é recomendável que a História da Filosofia e o texto filosófico tenham papel central no ensino de Filosofia”. ${ }^{6}$ Essa sugestão é ali apresentada como parte de um argumento que visa a estabelecer o que há de específico no empreendimento filosófico, daquilo que é peculiar à Filosofia e que, desse modo, serviria para distingui-la de todas as outras disciplinas do currículo escolar. Contudo, apesar de o recurso à História da Filosofia ser indispensável para qualquer curso sério de Filosofia - por ser o lugar onde estão os paradigmas do que sejam os conteúdos e métodos propriamente filosóficos - parece desnecessário afirmá-lo para justificar o espaço dessa disciplina nas escolas, algo que não está bastante claro naquele documento. Assim, é porque falar em Filosofia é já pensar imediatamente nos textos da tradição, com seus conteúdos e métodos próprios de proceder à investigação das mais variadas questões, e pelo fato de que a leitura desses textos desenvolve em nós aquelas capacidades (o pensamento crítico e a autonomia intelectual) que julgamos agradáveis por si mesmas - e como úteis para uma sociedade democrática como a nossa - que o recurso à História da Filosofia para a disciplina no ensino médio está plenamente justificado.

Com efeito, a Filosofia de que se fala no capítulo anterior é a Filosofia como tradicionalmente a conhecemos, a Filosofia a partir dos clássicos. Pois, em sentido estrito, o que nos autoriza a dizer de um problema que ele é de tipo filosófico? Ora, não pode ser senão o fato de ele, ou bem ter sido anteriormente tratado por um filósofo da tradição, ou bem ser tal que sua solução remete a um tipo de procedimento investigativo de que os textos filosóficos são o melhor exemplo. É porque a compreensão da primeira resposta do personagem Teeteto à questão 
"Que é conhecimento?" exige bastante reflexão (bem como a compreensão do projeto reconciliatório de Hume acerca do problema liberdade x necessidade nas ações humanas, ou do Argumento Ontológico de Santo Anselmo etc.) que o estudo da Filosofia desenvolve nos estudantes habilidades como a autonomia intelectual e o pensamento crítico. Ora, em todos esses casos, como em muitos outros, a História da Filosofia é o ponto de partida de nossas reflexões.

Portanto, à pergunta "O que se deve ensinar aos alunos do ensino médio nas aulas de Filosofia?", deve-se responder: "Seja qual for o conteúdo, ou bem ele deve ser retirado dos textos clássicos, ou bem ele deve exigir um tratamento de tipo semelhante àquele empregado pelos filósofos da tradição quando da realização de suas obras" (ou seja, uma investigação sistemática sobre lugares-comuns). O sucesso da Filosofia como disciplina escolar depende do rigor que os estudantes procederão em suas investigações, rigor cujo modelo é o texto clássico.

Ora, uma das consequências da centralidade da História da Filosofia para a disciplina no ensino médio, entre as quais a necessidade de formação específica para os professores da área, é que, diante da incômoda possibilidade de se fazer das aulas de Filosofia um lugar para doutrinação dos alunos, uma base histórica deverá assegurar que este não seja o caso. Isso está de acordo com o raciocínio exposto nas Orientações Curriculares, segundo o qual, por um lado, "a resposta de cada professor de Filosofia do ensino médio à pergunta 'que filosofia?' sempre dependerá da opção por um modo determinado de filosofar que considere justificado", 7 e que, por outro, "Essa adesão (...) tem alguma medida de controle na referência à História da Filosofia, sem a qual seu labor se tornaria mera doutrinação". ${ }^{8}$ Desse modo, ao mesmo tempo em que concede ao professor uma liberdade para elaborar o próprio planejamento, o recurso à História da Filosofia é um modo de garantir que nas aulas de Filosofia os alunos terão Filosofia e não outra coisa qualquer. Portanto, qualquer que seja o grau de aprofundamento, a História da Filosofia deve ter um papel central no ensino dessa disciplina, seja pelo seu aspecto positivo (por garantir que os conteúdos serão propriamente filosóficos), seja pelo seu aspecto negativo (no sentido de não abrir espaço para a doutrinação dos estudantes).

\section{II}

Contudo, do fato de que a História da Filosofia deve fornecer os conteúdos a serem trabalhados na sala de aula, não se segue que o acesso aos textos clássicos

7 Orientações Curriculares, p. 24.

8 Orientações Curriculares, p. 37. 
deve ocorrer já no momento de apresentação das questões filosóficas. Jogar no colo do aluno um exemplar da Crítica da Razão Pura como introdução ao problema acerca da possibilidade e dos limites do conhecimento humano certamente seria um absurdo. Em vez de despertá-lo para o exercício reflexivo, uma conduta desse tipo teria o efeito oposto. É por essa razão que se deve sempre começar os trabalhos em sala de aula com uma exposição bastante informal dos assuntos filosóficos, evitando-se a menção a nomes de filósofos e suas obras. Aquilo que era problema para Kant será também um problema para quem pensar sobre o que ele pensou. É preciso buscar os meios de estimular o aluno a realizar exercícios de pensamento como os que encontramos nos grandes tratados de Filosofia.

Desse modo, se o objetivo for introduzir uma investigação sobre usos falaciosos da argumentação, deve-se primeiro exemplificar os diferentes usos da linguagem; em seguida, pode-se recorrer a fatos literários, históricos, jurídicos, publicitários etc., para expor algumas das falácias mais comuns, algumas das quais nós mesmos cometemos ordinariamente. O recurso ao manual de lógica, no qual estão listados muitos desses maus argumentos, deve ocorrer apenas em um segundo momento, se for para os estudantes se envolverem realmente com o tema. De maneira análoga, uma aula cujo objetivo seja introduzir o conceito de realidade pode começar com a exposição de um filme que evidencie fenômenos ou entidades com as quais não estamos acostumados. Isso, aliás, serve para todos os campos da Filosofia. Enfim, pode-se recorrer a uma grande quantidade de instrumentos para introduzir um tema filosófico, basta que o professor seja um pouco criativo. Somente após essa introdução e um esforço inicial dos alunos para responderem às questões é que se deve apresentar o tratamento dos grandes filósofos a tais questões.

Chegados a esse ponto, poderíamos listar uma série de estratégias pedagógicas para a boa condução das aulas de Filosofia. Não queremos, porém, perder de vista o caráter filosófico deste trabalho, cometendo os mesmos erros que outros acabaram por se enredar. ${ }^{9}$ Defender que esta ou aquela metodologia é a correta ou mais adequada é desnecessário: basta que se defenda o espírito geral que

\footnotetext{
9 Em relação a esse ponto, vale uma referência a Matthew Lipman. Em A Filosofia Vai à Escola, ele afirma: "As escolas de educação parecem continuamente em luta com crises de identidade. Como adolescentes, parecem estar constantemente experimentando novas personalidades, dependendo do que lhes parece estar momentaneamente na moda. Num momento é dinâmica de grupo, em outro é manejo de sala de aula, ou lado direito ou lado esquerdo do cérebro, ou alguma outra panaceia temerária e de vida curta. Se a educação do futuro tiver de ter substância, a educação dos professores irá requerer mais integridade do que tem atualmente. Terá de descobrir sua própria identidade, seu próprio senso de direção, e isso deve lhe dar um sentido de proporção em termos de como distribuir suas energias em relação à hierarquia de seus interesses" (p. 44).
} 
deve nortear as aulas de Filosofia no ensino médio. Se, de fato, "a experiência é conhecimento dos singulares, e a arte, dos universais", ${ }^{\circ}$ contentamo-nos em indicar que, seja qual for o procedimento pedagógico a ser empregado pelos professores da área, ele terá de respeitar a regra segundo a qual não se deve expor os alunos aos textos filosóficos clássicos antes de lhes ter despertado o interesse nos problemas tratados nesses textos, sem o que os estudantes jamais teriam a atenção necessária para desenvolver aquelas habilidades de pensamento que julgamos valiosas. ${ }^{\text {II }}$

Assim, é por impedir que o aluno se empenhe na leitura e análise dos textos e problemas filosóficos clássicos (o que é uma das vias para se chegar ao desenvolvimento do pensamento crítico e da autonomia intelectual) que o contato prematuro com esses textos deve ser evitado pelos professores. Trata-se, pois, de uma questão de ordem psicológica. Isso significa, entre outras coisas, que o professor de Filosofia não poderá proceder no ensino médio do modo como os professores universitários procedem, por maior que seja sua tentação de repetir na escola a maneira pela qual foi ensinado: "o profissional bem formado em licenciatura não reproduzirá em sala a técnica de leitura que o formou, transformando o ensino médio em uma versão apressada da sua graduação". ${ }^{12}$

Com base nessas considerações, pode-se concluir que os conteúdos a serem trabalhados pela disciplina em nível médio devem ter origem na História da Filosofia, onde encontramos os casos paradigmáticos do que seja uma investigação sistemática, e a metodologia a ser empregada pelo professor consistirá inicialmente na exposição de um problema filosófico de maneira bastante informal (i.e., sem o recurso às grandes obras) e, somente então, se isso parecer relevante, na leitura dos grandes tratados filosóficos em que tal problema foi abordado. ${ }^{13}$

IO ARISTÓTELES. Metafísica; tradução de Vincenzo Cocco, São Paulo, Abril Cultural, I979, p. I2. II Quanto a esse ponto, alguém poderá se mostrar cético, dizendo que mesmo nos cursos de Graduação em Filosofia as aulas já começam com a leitura dos clássicos sem que se introduza o problema a que aquela obra visa responder. Segundo nos parece, isso não apenas não justifica um procedimento de mesmo tipo nas escolas, como mostra que muito há que se melhorar também nos cursos universitários. I2 Orientações Curriculares, p. 33.

I3 Em relação a esse ponto, vale um esclarecimento. Não há dúvida de que existem outras escolas filosóficas diferentes daquela dentro da qual este trabalho vem se desenvolvendo (com a minha formação), as quais não apenas desconsideram a História da Filosofia como algo essencial para a atividade filosófica, como também dizem que fazer da Filosofia um estudo de teorias passadas (isto é, superadas, segundo essa análise), seria ir de encontro à natureza mesma da Filosofia, um empreendimento crítico que, por essa precisa razão, não deve se restringir à análise e possível defesa de sistemas filosóficos obsoletos. Em resposta a esse argumento, só conseguimos pensar que, a despeito do fato de algumas posições 
Eis, portanto, algumas considerações cujo objetivo é o de responder por que, o que e como se deve ensinar Filosofia para os jovens no ensino médio. Sem dúvida, essas questões estão estreitamente relacionadas, e aquele que defende o espaço dessa disciplina nas escolas com a esperança de ser escutado tem de se enredar nas dificuldades despertadas por cada uma daquelas interrogações. Felizmente ou não, a Filosofia se mostrou um excelente recurso educacional. Mas o caráter ainda incipiente desta pesquisa indica que muito há que se pensar sobre o assunto. Seja como for, deu-se aqui um primeiro passo. E isso não é mais do que por ora se almeja.

\section{Referências Bibliográficas}

ARISTÓTELES. Metafísica, São Paulo, Abril Cultural, I979.

FISHER, Alec. A Lógica dos Verdadeiros Argumentos, São Paulo, Novo Conceito Editora, 2008.

LIPMAN, Matthew. A Filosofia vai à Escola, São Paulo, Summus Editorial, I990.

KOHAN, Walter. "Três lições de filosofia da educação" (In: Educação \& Sociedade, vol. 24, n. ${ }^{\circ}$ 82, Campinas, Abril 2003).

NAGEL, Thomas. Uma Breve Introdução à Filosofia, São Paulo, Martins Fontes, 2007.

RACHELS, James. Elementos de Filosofia Moral, Lisboa, Gradiva, 2004.

SEGRETARIA DA EDUGAÇÃO BÁSICA. Orientações Curriculares para o Ensino Médio, Brasília, Ministério da Educação - Brasil.

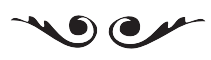

Thiago Cruz da Silva é graduando em Filosofia pela UFRS.

E-mail:tcs020@yahoo.com.br

filosóficas serem hoje insustentáveis, disso não se segue que porque Aristóteles é anterior aos filósofos do círculo de Viena que ele, Aristóteles, foi superado por tais filósofos. Utilizar um critério meramente temporal, ao que parece, é que não tem nada de crítico. Visto que para debater com posições semelhantes a essa seria preciso muito mais pesquisa e tempo. 